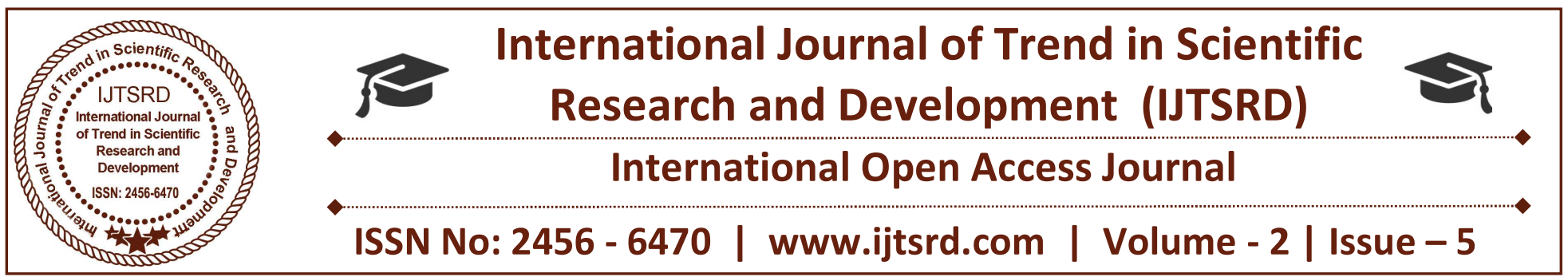

\title{
Design and Control of Automatic Power Factor Correction (APFC) for Power Factor Improvement in Oakshippin Primary Substation
}

\author{
Thida Win Ngwe ${ }^{1}$, Soe Winn², Su Mon Myint ${ }^{3}$ \\ ${ }^{1} \mathrm{ME}$ Student, ${ }^{2}$ Professor, ${ }^{3}$ Lecturer \\ Department of Electrical Power, Pyay Technological University, Myanmar
}

\begin{abstract}
This paper present a new method for power factor correction and the effect of shunt compensation for various loads. For the system stability and reliability, the reactive power compensation is essential for power system. Among of VAR compensation system, the automatic power factor correction is one of the compensation systems. Power factor control is a major role in the improvement of power system stability. Many of the existing systems are expensive and difficult to manufacture. Fixed capacitor systems are always leading power factor under at any load conditions. This is unhealthy for installations of power system. The proposed system used to reduce the cost of equipment and increase the efficiency of the system.
\end{abstract}

KEYWORD: Reactive Power Compensation, VAR compensator, PF Improvement, Shunt Capacitor, Switching Relay Driver

\section{INTRODUCTION}

The electric power system has grown in size and complexity with a huge number of interconnections to meet the increase in electric power demand. Moreover the power quality is now becoming a major concern among users and utilities, forcing the development and application of more stringent standards due to the connection of more sophisticated loads. Due to this today's changing electric power systems create a growing need for flexibility, reliability, fast response and accuracy in the fields of electric power generation, transmission, distribution and consumption.

There are so many industries around the world and so are in Myanmar. Most of the industrial plants are using the inductive loads in infrastructure such as transformers and motors. Among them, the large industrial motors are essentially used in the industrial plants. Induction motors receive the grate reactive power from network for their proper function. The inductive load is act as a lagging power factor. The result of lagging power factor increases the power losses in the power system. Reactive power consumption causes the reduction of voltage and power factor in the networks. The reactive power is compensated by using suitable value of capacitors.

The existing work on power factor correction is having some disadvantages like switching operations and sensing stability of the system. In this proposed system is used to rectify the above problem. Power factor is the cosine angle between the voltage and current. This currents and voltages are sensed by instrument transformers like current transformer and potential transformer. In this proposed method zero crossing detectors is used to converting the sinusoidal waveforms of voltage and current into square waveform. The above square waves are fed into the PIC 18F4550 microcontroller. The phase angle between the voltage and current are calculated by microcontroller.

The calculated values are comparing with actual load present in the system. The power factor of the load on the system is optimal when the capacitor bank is added in the system by using microcontroller. These processes are continuously carried out and maintain the desired power factor in automatically. 


\section{A. Problem Statement}

The need of a stable power system is increasing rapidly throughout the years. To make sure the power system is stable and reliable, there need to be protective devices installed on the network, such as compensator. The technical problem can be the application of capacitors. An effort will have to study the compensator used in the system of the electricity utility network.

\section{B. Objectives and Scope}

This paper aims reactive power compensation using automatic power factor correction (APFC) in substations as voltage quality is the issue of the electrical engineering. This paper is concentrating on the new technologies based concepts because these devices are capable of mitigating several voltage quality problems.

The objectives of the papers are;

1. to understand the sensing device of control system

2. to design a microcontroller based correction equipment to improve the power factor of the system

3. to analyze the system performance with and without compensator installed.

Scopes of the paper are as follows:

1. This project is focused on the OAKSHIPPIN primary substation in Myanmar.

2. This type of compensator to be studied is restricted to the automatic power factor correction with capacitor bank.

3. This project considered for maximum power consumption to correct power factor.

\section{TECHNOLOGY}

Automatic power factor controller is designed to improve power factor automatically when power factor falls below a certain level. Whenever power factor below fall desired level, the microcontroller send signal to relay driver and switch on relays. By turning on relays, capacitor bank connects automatically to load and improve power factor. Block diagram of proposed system is shown in Figure (1).

\section{TECHNICAL SPECIFICATIONS}

Power Supply, Potential Transformer, Current Transformer, Zero Crossing Detector, PIC18F4550 Microcontroller, Relay Driver, Relay, LCD Display,
Switching Capacitors are main equipment used in this APFC system.

A. Power Supply - The AC input is supplied to the primary of a step down voltage transformer. The output of transformer is connected to the diode which acts as a rectifier. Microcontrollers operate on 5V DC. If microcontroller is made to be operated upon the voltage greater than 5 volts, it will burn out and damage immediately.

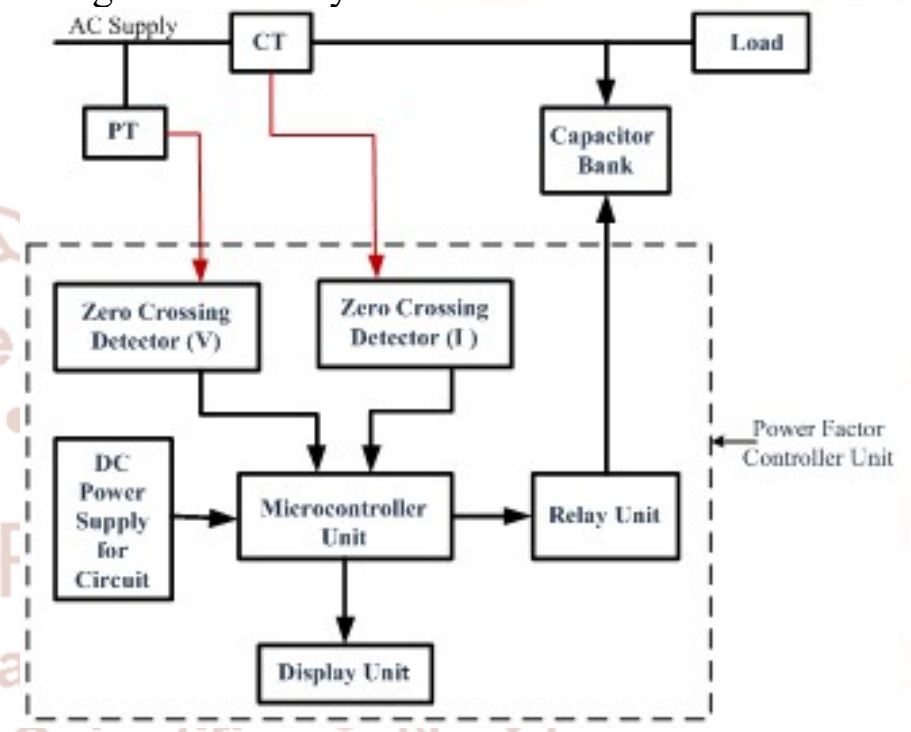

Figure.1. Block Diagram of Automatic Power Factor Controller

B. Potential Transformer Potential Transformer (PT) - The PT used steps-down the supply voltage to require voltage by the circuit to operate. Microcontrollers cannot operate upon voltages which are greater than $5 \mathrm{~V}$. If microcontroller is made to be operated upon the voltage greater than $5 \mathrm{~V}$, it will burn out and damage immediately. The PT is used to step down voltage for measurement, control and protection.

C. Current Transformer (CT) - A step down current transformer is used to convert high current into low current for the use of different electrical circuits. The current transformer is also used for detection measurement, protection of the system.

D. Zero Crossing Detector-. The outputs from current and voltage transformers are fed to zero crossing detector which will convert the sinusoidal waveform to square waveform. The reference voltage in this case is set to zero. The output voltage waveform shows when and in what direction an input signal crosses zero volts. If input voltage is a low 
frequency signal, the output voltage will be less quick to switch from one saturation point to another. And if there is noise in between the two input nodes, the output may fluctuate between positive and negative saturation voltage Vsat. The zero crossing is detected and an output signal is generated which is sent to the microcontroller. The current and voltage signals are taken the phase for measuring the power factor [5]. The Op-amp LM358 is used as zero crossing detector.

\section{Figure.2. Block Diagram of Zero Crossing Detectors}

E. Microcontroller - PIC18F4550 microcontroller is the heart of the APFC. The use of the microcontroller is to perform various calculations, to take decisions and give relative output. The current and voltage received from zero crossing detectors are compared in microcontroller to calculate phase difference between two signals and ultimately the power factor. The calculated power factor will be sent to LCD display and on the basic of present valued of power factor, the decision will be taken by microcontroller for capacitor switching.

F. Liquid Crystal Display - LCD is very basic module and is used very commonly in various circuits for display purpose. LCD display is preferred over LED display and seven segment display. LCD's are easily programmable, economical and can easily display characters, animations. A $16 \times 2$ LCD display LM016L is used which will be displaying current, voltage, power and power factor.

G. Relay Driver - It is a component that permits a low power circuit to control signals. The relay driver is used in the circuit because the relays required the higher amount of current. The relays cannot be directly control by microcontroller. ULN 2003A Darlington Transistor driver is used for current amplification purpose which provides higher current and which drive the relays

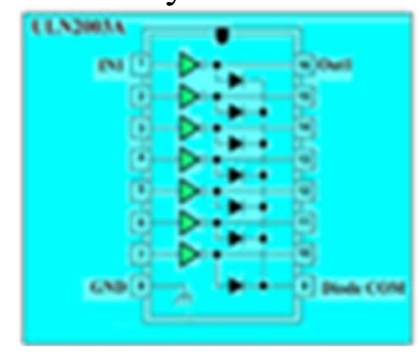

Figure.4. Relay Driver IC ULN 2003A Internal Schematic Diagram

H. Relay - An electrically operated switch is known as relay. The initial state, they are used in normally open. If they receive signal from microcontroller they close and connect the relative capacitor in the circuit.

I. Capacitor - Capacitors add reactive load in the circuit which will help to increase power factor for energy supplementation devices. Number of capacitors which are to be added depends upon the power factor of the circuit. When the power factor drops from a specific value, the relay will act to add capacitor to the circuit. If power factor value drops a little to the prescribed value then one capacitor is added. In case of power factor drops much more than prescribed value then second capacitor is also added and the system goes on this way. The circuit will continue to add capacitor in parallel to the load until a good value of power factor is achieved.

\section{CIRCUIT DIAGRAM OF THE SYSTEM}

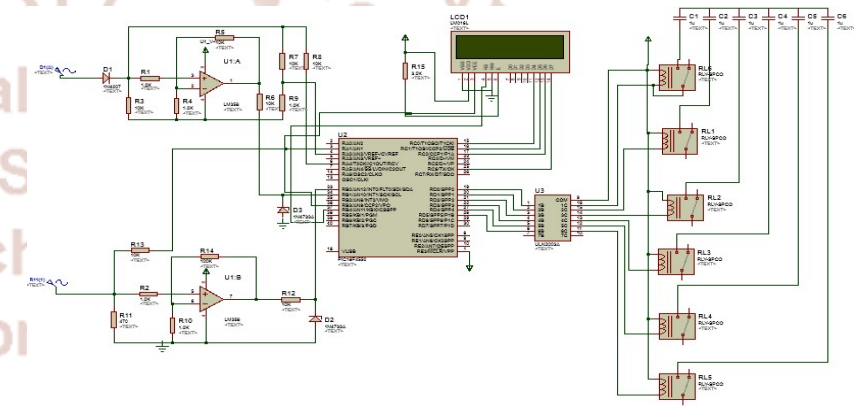

Figure.5. Automatic Power Factor Controller Circuit

\section{FLOW CHART OF THE PROPOSED SYSTEM}


International Journal of Trend in Scientific Research and Development (IJTSRD) ISSN: 2456-6470

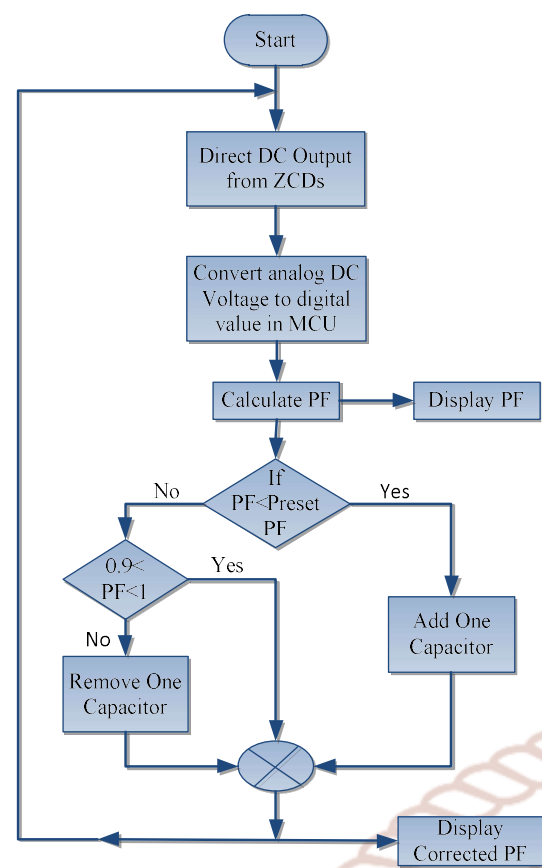

Figure.6. Power Factor Calculating Flowchart V. DESIGN CALCULATION

It is proposed to study the effect of shunt compensation provided for different loads, catered from substation, to assess its adequacy and saving in transmission losses. For power factor improvement, the detail study and data collection is carried out at Oakshippin primary substation.

This substation has 7 main feeders. They are 5MVA NYAUNGCHAYDAUK feeder, 25MVA MYANAUNG, 5MVA KAMYAING feeder, 15MVA MATHON feeder, 5MVA KAMMA feeder, 10MVA SINDE feeder, 315kVA OAKSHIPPIN feeder. The single line diagram, load data and load cycle curve are shown in the figures and tables.

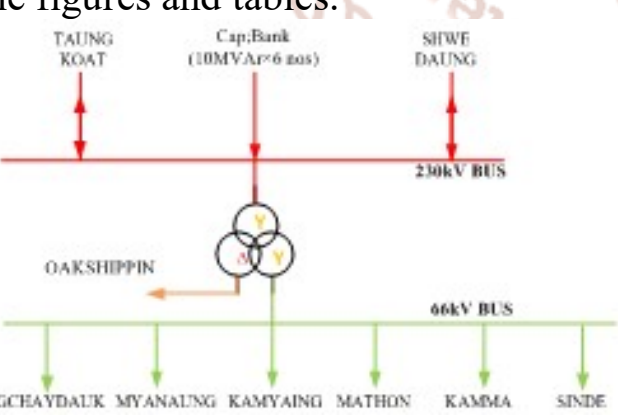

Figure.7. the single Line Diagram of Oakshipp in Primary Substation $(230 / 66 / 11 k V)$

Table: Daily Load Power Data (Maximum, Minimum, Average) collected in Oakshippin primary Substation

\begin{tabular}{|c|c|c|c|c|}
\hline \multirow{2}{*}{ No. } & \multirow{2}{*}{ Name } & \multicolumn{3}{|c|}{ Power (MW) } \\
\cline { 3 - 5 } & & Max & Min & Avg; \\
\hline 1 & Nyaungchaydauk & 1.8 & 0.45 & 1.24 \\
\hline 2 & Mathon & 1.7 & 0.78 & 1.53 \\
\hline
\end{tabular}

\begin{tabular}{|c|c|c|c|c|}
\hline 3 & Myanaung & 26.3 & 10.1 & 18.97 \\
\hline 4 & Kamyaing & 2.9 & 1.6 & 2.24 \\
\hline 5 & Kanma & 0.98 & 0.28 & 0.583 \\
\hline 6 & Sinde & 6.5 & 2.1 & 3.8 \\
\hline 7 & Oakshippin & 0.03 & 0.013 & 0.022 \\
\hline & Total & 40.21 & 15.33 & 28.39 \\
\hline
\end{tabular}

Daily Load Curve of Oakshippin Primary Substation

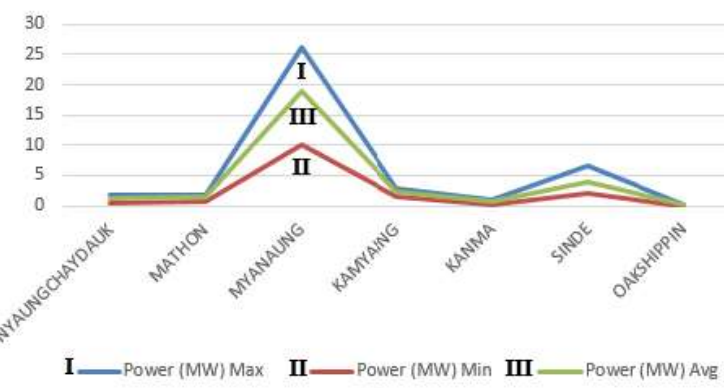

Figure.8 Daily Load Curve of Primary Substation, Oakshippin.

Table: Observation of MVAR and Power Factor (PF) during stages of operation of capacitor banks provided on $230 \mathrm{kV}$ bus of $230 \mathrm{kV}$ Primary Substation, Oakshippin.

Power Transformer Capacity: 3×33.33MVA, $230 / 66 / 11 \mathrm{kV}$, Capacity of shunt capacitor bank installed at $230 \mathrm{kV}$ bus: $(10 \times 6)=60 \mathrm{MVAr}$

\begin{tabular}{|c|c|c|c|}
\hline No. & $\begin{array}{c}\text { Stages of Operation of } \\
\text { Capacitor Banks }\end{array}$ & $\begin{array}{c}\text { MV } \\
\text { AR }\end{array}$ & PF \\
\hline $\begin{array}{c}\text { Stag } \\
\text { e-1 }\end{array}$ & Without any capacitor Bank & 74.7 & $\begin{array}{c}0.4 \\
74\end{array}$ \\
\hline $\begin{array}{c}\text { Stag } \\
\text { e-2 }\end{array}$ & $\begin{array}{c}\text { With 5MVAr Capacitor Bank } \\
\text { x 1 no }\end{array}$ & 64.7 & $\begin{array}{c}0.5 \\
3\end{array}$ \\
\hline $\begin{array}{c}\text { Stag } \\
\text { e-3 }\end{array}$ & With 5MVAr Capacitor Bank & 54.7 & $\begin{array}{c}0.5 \\
9\end{array}$ \\
\hline $\begin{array}{c}\text { Stag } \\
\text { e-4 }\end{array}$ & $\begin{array}{c}\text { With 2nos } \\
\text { x }\end{array}$ & 44.7 & $\begin{array}{c}0.6 \\
7\end{array}$ \\
\hline $\begin{array}{c}\text { Stag } \\
\text { e-5 }\end{array}$ & $\begin{array}{c}\text { With 5MVapacitor Bank } \\
\text { x 4nos }\end{array}$ & 34.7 & $\begin{array}{c}0.7 \\
6\end{array}$ \\
\hline $\begin{array}{c}\text { Stag } \\
\text { e-6 }\end{array}$ & $\begin{array}{c}\text { With 5MVAr Capacitor Bank } \\
\text { x 5nos }\end{array}$ & 24.7 & $\begin{array}{c}0.8 \\
5\end{array}$ \\
\hline $\begin{array}{c}\text { Stag } \\
\text { e-7 }\end{array}$ & $\begin{array}{c}\text { With 5MVAr Capacitor Bank } \\
\text { x 6nos }\end{array}$ & 14.7 & $\begin{array}{c}0.9 \\
4\end{array}$ \\
\hline
\end{tabular}

In stage I: Without any capacitor bank connect in substation.

In stage II: Capacitor bank-1 at substation is initially kept "ON", reactive power reduces to 64.7MVAr and power factor improve to 0.0.53.

In stage III: Capacitor bank-1 and 2 are kept "ON", reactive power reduces to54.7MVAr and power factor 
improve to 0.59. And it is going step by step to desired power factor.

In stage VII: $10 \mathrm{MVAr} \times 6$ nos capacitor banks are "ON", in this stage reactive power is reduced from 74.7 to 14.7 and power factor is increased up to 0.94 .

Figure (9) shows the improvement of power factor in substation.

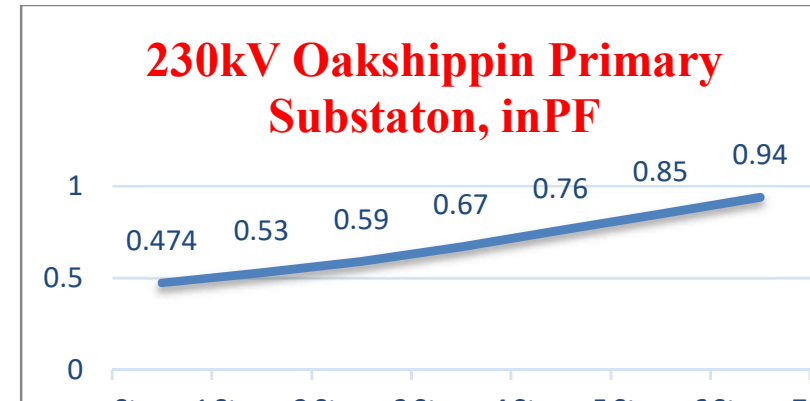

Stage-1 Stage-2 Stage-3 Stage-4 Stage-5 Stage-6 Stage-7

Figure.9 Effect due to Stages of Operation of Capacitor Banks in Primary Substation,

VI. CONCLUSION

Oakshippin.

It can be concluded that power factor correction techniques can be applied to the power system and due to that the system becomes stable and reliability of the system. The use of microcontroller reduces the cost and eliminates the extra hardware devices. In this research, capacity of shunt capacitor bank (10MVAr $\times 6$ ) installed at $230 \mathrm{kV}$ line in Oakshippin primary substation. Capacitor banks have generated reactive power and requirement of reactive power drawl from the system reduces it further reduces the corresponding amount of current in the line. Therefore applications of capacitor banks on substation, reduces the reactive power flow and reduce the losses in square proportion. In result, improvement in power factor from 0.474 to 0.94 and reactive power reduce 74.7 to 14.7 in stage -7 .

\section{ACKNOWLEDGEMENTS}

First and foremost, the author would like to thank Professor, Dr. Nyunt Soe, Rector, Pyay Technological University for his permission to carry out the thesis. The author gratefully acknowledge to Dr. Soe Winn, Professor and Head, Department of Electrical Power Engineering, Pyay Technology University for his encouragement, advice and continuous guidance throughout the study the author of this paper is greatly thankful to U Than Zaw Htwe, Lecture, Department of Electrical Power Engineering, Yangon Technology University for his time, expertise and continued support. Then the author also wishes to extend special thanks to all her teachers from Department of
Electrical Power Engineering, Pyay Technological University for giving understanding, helpful guidance, suggestions and directions throughout the preparation of work.

\section{REFERENCES}

1. en.wikipedia.org/wiki/Power factor correction

2. Hadi Saad, "Power System Analysis"

3. T. J. E. MILLER, "Reactive Power Control in Electric Systems"

4. John J, Grainger, William D. Stevenson, "Power System Analysis," TaTa Mcgraw Hill 2003, New Delhi, India.

\section{SAIRAJ} GHARAT1, DARSHANA PATILKHEDE2, SANKET PATIL3, ABHISHEK YADAV4, "Automatic Power Factor Correction Using Microcontroller" International Journal of Engineering Technology Science and Research (IJETSR), Volume 4, Issue 4, April 2017.

6. Asst. Prof. Smitha Paulose1, Ann Mary George2, Linu Jose3, Sruthi Harikumar4, "Reactive Power Compensation Using SVC" International Research Journal of Engineering and Technology (IRJET) Volume: 03 Issue: 06 June-2016.

7. Ms. Kavathekar Jyoti S., M S Kambale Madhuri D., "Automatic Power Factor Relay using PICController" International Journal of Advanced Research in Electronics and Communication (IJARECE) Volume 5, Issue 4, April 2016.

8. Aparna Sarkar, Umesh Hiwase "Automatic Power Factor Correction by Continuous Monitoring" International Journal of Engineering and Innovative Technology (IJEIT) Volume 4, Issue 10, April 2015.

9. Mr. Anant Kumar Tiwari, Mrs. Durga Sharma, Mr. Vijay Kumar Sharma "Power Factor Correction Using Capacitive Bank", Int. Journal of Engineering Research and Applications ISSN: 2248-9622, Vol. 4, Issue 2(Version 1), pp.393395, February 2014.

10. Anagha Soman, Assistant Professor, Pranjali Sonje, "Power Factor Correction Using PIC Microcontroller", International Journal of Engineering and Innovative Technology (IJEIT) Volume 3, Issue 4, October 2013.

11. Rajib Baran Roy, "Design of Microcontroller Based Static VAR Compensator" International 
Journal of Scientific \&Engineering Research, Volume 3, Issue 11, November-2012.

12. Barsoum Nader "Programming of PIC MicroController for Power Factor Correction" IEEE Conference on Modeling \& Simulation, Pages: 19-25, March 2007.

13. Ramasamy Natarajan (2005). "Power System Capacitors." Boca Raton, FL: Taylor \& Francis.

14. Kim, T. W.; Choi J. H.; Kwon, B. H., "HighPerformance Line Conditioner with Output Voltage Regulation and Power Factor Correction", IEEE Proceedings on Electric Power Applications, Volume: 151, Issue: 1, Pages: 91- 97, January 2004.

15. Juan Dixon (SM), Luis Moran (F), Jose Rodriguez (SM), and Ricardo Domke: "Reactive Power Compensation Technologies, State-of-the-Art Review, 2000. 